\title{
Component Analysis and Calculation for Social Benefits of UHV Assessment
}

\author{
Jingshan Luo ${ }^{1,2}$, Dichen Liu1 ${ }^{1}$, Jun Wu ${ }^{1}$, Fan Gao', Qixin Wang1, Kai Wang1, Xuedong Zhu1 \\ ${ }^{1}$ School of Electrical Engineering, Wuhan University, Wuhan, China \\ ${ }^{2}$ State Power Economic Research Institute, Beijing, China \\ Email: ^byronwu@whu.edu.cn
}

How to cite this paper: Luo, J.S., Liu, D.C., Wu, J., Gao, F., Wang, Q.X., Wang, K. and Zhu, X.D. (2016) Component Analysis and Calculation for Social Benefits of UHV Assessment. Smart Grid and Renewable Energy, 7, 261-269.

http://dx.doi.org/10.4236/sgre.2016.710020

Received: September 20, 2016

Accepted: October 21, 2016

Published: October 24, 2016

Copyright $\odot 2016$ by authors and Scientific Research Publishing Inc. This work is licensed under the Creative Commons Attribution International License (CC BY 4.0).

http://creativecommons.org/licenses/by/4.0/

\begin{abstract}
With the rapid development of the UHV power grid, evaluation of the economic and social benefits of the UHV power grid is conducive to guiding the planning and construction of UHV power grid. At present economic benefit evaluation system of the UHV power grid is driving to maturity stage on the whole at home and abroad, but it invariably tends to regard social benefits as part of economic benefits, without evaluating social benefit separately. The social benefit evaluation model of UHV power grid is built in case of sufficient investigation. The differentials between social benefit and social cost are calculated respectively by three kinds of solutions according to the constructed social cost evaluation index system and social benefits evaluation index system, conclusion that UHV power grid transmission has better social benefits can be reached by contrastively analyzing the social three kinds of solutions corresponding to benefits. At last, the evaluation model and method are verified and analyzed through the analysis of engineering projects.
\end{abstract}

\section{Keywords}

UHV Power Grid, Social Benefit Assessment Model, Contrastive Analysis, Social Cost, Social Income, Planning and Construction

\section{Introduction}

With the rapid development of UHV power grid, the analysis of the operational factors [1] and the economical assessment of UHV power grid are crucial in planning and constructing the UHV power grid. Currently, the main method for economical assessment is based on the discounted cash flow. The assessment is done by the Net Present Value (NPV) while the relevant economic indicators are obtained by the Internal Rate of Return (IRR) as well as the payback period method, and the benefits and costs are 
compared in Ref [2] [3]. The Ref [4] utilizes the optimal power flow calculation method to evaluate economic during the whole life cycle. In the Ref [5], the UHV transmission model is built and the economic analysis is done.

At present, the economic evaluation system is almost mature. However, either the current economic evaluation methods cover the economic benefits assessment and the social benefits assessment at the same time, or some social indicators and contents are part of indirect economic benefit, So the traditional methods have some obvious shortcomings: First, social benefits and influence cannot be completely measured because of the lack of related social benefits; Second, it is difficult to distinguishing the cost and the benefit, causing the inaccurate assessments; Third, considering some specific social benefits of UHV, evaluation indicators are not completely suitable for economic evaluation; Fourth, to develop the environmentally friendly society and promote the sustainable development, stricter requirements for controlling urban smog and PM2.5 have been put forward, thus simple economic evaluation cannot meet the demand. Therefore, reasonable social benefits evaluation system should be built for current UHV and provide scientific basis for the project feasibility studies.

It can be concluded that direct and indirect social benefit evaluation models should be established under the engineering practice of UHV. In this paper, social benefits and social costs evaluation indicators systems are built first. And then, under the situation of transferring the same amount of electricity energy, 3 cases are applied, namely the UHV, the $500 \mathrm{kv}$ transmission and the $500 \mathrm{kv}$ transmission with coal (the coal will be converted to electricity after transported to load centers). After that the direct social benefit of the 3 cases is calculated from the cost and benefit, the indirect social benefit is of the 3 cases obtained by the comparison and analysis, finally, the evaluation model and method are verified and analyzed respectively in the analysis of engineering projects.

The rest of this paper is organized as follows: In Section 2, social benefits evaluation model is built. Section 3 introduces social income evaluation index system. In Section 4, the social cost evaluation index system is introduced. And the assessment model and method is examined In Section 5.

\section{Social Benefits Evaluation Model}

The social benefits (SBs) assessment of UHV is different from others when taking the practical engineering of the UHV and the distinguished characteristics of the UHV into consideration. The social benefits (SE) of the UHV are evaluated thoroughly in this paper. To begin with, the direct social benefits are compared between the three possible transmission ways of the UHV from the vertical perspective regarding the social incomes and social costs. Moreover, the indirect social benefits are assessed thorough comparative analysis of the direct social benefits from horizontal angle. The vertical and horizontal methods are working in a complementary manner, among which the vertical assessment is supposed to emphasizing on the specificities of the social benefit assessment, while the horizontal assessment is capable of demonstrating the increment part is consistent with the principles of economics. 
Combined with engineering practical of UHV, the social costs (SCs) are evaluated from longitudinal and horizontal two aspects, direct social costs (DSCs) index system is divided into four segments namely the environment cost (ENC), energy cost (EC), land cost (LC) and human resources cost (HRC), ENC includes carbon emission costs (CECs), carbon trading costs (CTCs) and emissions abatement costs (EACs), EC includes freshwater resources consumption costs (FRCCs) and generation resources costs (GRCs), LC includes Taki area of compensation costs (TACCs) and plant land acquisition costs (TACCs), HRC includes development and transmission of human resources costs (DTHRCs) and transmission line maintenance costs of human resources (TLMCHRs); Indirect social costs (ISCs) index system includes audible noise reduction cost (ANRC) and social power outages loss cost (SPOLC); At last, social income (SI) assessment index system consists of create industrial benefits (CIBs) and create employment benefits (CEBs). Social costs and social benefits evaluation index system of UHV are illustrated in Figure 1.

Social costs of UHV can be obtained as in Equation (1).

$$
E_{c}=\sum_{i=1}^{4} \sum_{k=1}^{I_{k}} E_{i k}+\sum_{i=1}^{2} E_{1 i}
$$

$I_{k}$ is the number of the $i$ th direct costs, $E_{i k}$ is the $k$ th direct costs under the $i$ th direct costs.

Social income of UHV power grid as in Equation (2).

$$
E_{s}=E_{s 1}+E_{s 2}
$$

$E_{s 1}$ denotes the CIBS and $E_{s 2}$ means CEBs.

Direct social benefits can be got as in Equation (3).

$$
E=E_{s}-E_{c}
$$

\section{Social Income Evaluation Index System}

\subsection{Create Industrial Benefits}

Create industrial benefits (CIBs) can be obtained through calculating create average value of $1 \mathrm{kwh}$ in load center and the number of electrical power delivered to the load center, as in Equation (4).

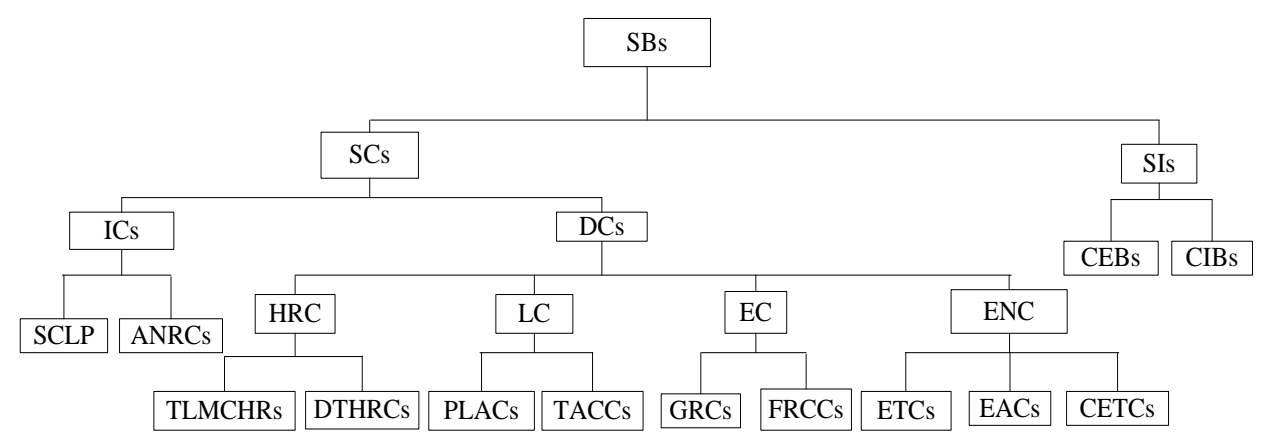

Figure 1. Social benefit estimation model for UHV grid. 


$$
E_{s 1}=S_{w e 0} c_{c}
$$

$c_{c}$ refers to the created average industrial value of $1 \mathrm{kwh}$ in load center, $S_{\text {we }}$ is the number of electrical power delivered to the load center.

\subsection{Create Employment Benefits}

CEBs include DEBs and IEBs. DEBs can be calculated through one trillion investment creating 11.59 million jobs and the wage of each worker is obtained from our country's per capita income under the current investment structure, as in Equation (5).

$$
E_{\text {s2z }}=T_{\text {tou }} \times \overline{N_{\text {tou }}} \times \overline{c_{r}}
$$

$T_{\text {tou }}$ is the invest cost when the capacity of $S_{\text {we }}$ energy transported to load center, $\overline{N_{\text {tou }}}$ is employment number per invest, $\overline{c_{r}}$ is GNI per capita.

IEBs refer to the added employment number through resolving lack electricity problem when electricity is transported to load center, as in Equation (6).

$$
E_{s 2 j}=S_{w e 0} \times C_{c} \times \eta
$$

$\eta$ is the ratio between China's per capita creation value and per capita income.

\section{Social Cost Assessment Index Systems}

\subsection{Direct Social Cost Assessment Index System}

Environmental pollution has become an important factor that restricts the development of today's economy, reducing $\mathrm{CO}_{2}$ emissions is an effective way to protect environmental, constructing environment-friendly society is an important component to achieve the dream of China, UHV power grid can well reduce pollution gases emission, large number of ENs is saved. ENs includes CETCs and EACs. Wherein the CETCs include the process of electricity transport, transport tool in coal transport and coal is left behind during transport, EACs refer to nitrogen oxides and soot emissions sewage costs in the process of thermal power plants.

$$
E_{1}=\left(F_{T}+F_{t}+F_{L}+S_{w e} m_{0} k_{1}\right) c_{t}+S_{w e}\left(m_{0} k_{2} c_{2}+k_{3} c_{3}+m_{0} k_{4} c_{4}\right)
$$

where $F_{T}, F_{t}, F_{L}$ are carbon emission in the process of electricity transmission, coal transport, coal is left behind in [6], $c_{t}$ is $\mathrm{CO}_{2}$ trading price, $S_{w e}$ is generating capacity, $k_{1}, k_{2}, k_{3}, k_{4}$ is respectively conversion factor of carbon dioxide, nitrogen oxides, water and dust, $c_{2}, c_{3}, c_{4}$ is charges standard respectively in [7], $m_{0}$ is coal consumption per product $1 \mathrm{kwh}$ electric energy.

China is a country that relatively lack in fossil energy and freshwater resources, coupled with inverse distribution between China's energy base and load center, not only add transport press, but also waste energy if energy is transported directly to the load center, which is not conducive to China building a resource-saving society. Thus reducing EC contribute to sustainable development of society, the construction of UHV power grid can solve these problems. EC of UHV includes ETCs, FRCCs and GRCs. Within ETCs include electricity and coal transmission cost, as in Equation (8). 


$$
E_{2}=E P_{L 1}+E P_{m 1}=S_{w e 1} r p_{t e}+\sum_{i \in I_{N}}\left(S_{w e}-S_{w e 1}\right) m_{T} C_{I_{N i}} \eta_{i}
$$

$E P_{L 1}, E P_{m 1}$ is transmission cost of electricity and coal respectively, $S_{w e 1}$ is energy through transmission line from energy base to load center, $r$ is the ration between thermal power transmission capacity and total transmission capacity, $p_{t e}$ is the life cycle cost for per transmission capacity, $I_{N}$ is vehicle collection, is transport costs through using transport tool, $C_{I_{N i}}$ is transport coal capacity ration between transport tool $i$ and total tool, $m_{T}$ is the average coal consumption of fossil fuel in power generation.

$$
E_{3}=S_{w e} V_{s} c_{s}
$$

Within $V_{s}$ is water consumption per generation, $c_{s}$ is per water price.

GRCs as in Equation (10) include transmission losses and power generation consumption cost.

$$
E_{4}=\sum_{i \in I_{N}} \mu_{i} L_{i} m c_{L}+\sum_{i=1}^{N_{0}} \lambda_{i} L_{i} S_{w e} \Delta c_{L}+S_{w e} m_{0} c_{m 0}
$$

within $\mu_{i}$ is unit distance coal spill rate through using vehicle transportation $i, \lambda_{i}$ is line loss rate per hundred $\mathrm{km}, \Delta c_{L}$ is loss price related to transmission distance in [8], $c_{m 0}$ is per coal price, $c_{L}$ is coal price gap between energy base and load center, $N_{0}$ is transmission line number.

Lack of land resources in our country, land resources is of great significance to the economy sustainable development. LC of UHV includes TACCs and PLACs. TACCs in Equation (11) through using engineering experience and actual situation.

$$
E_{5}=L_{L} K_{G} S_{G} M_{S}
$$

$L_{L}$ is the construction feasibility study or preliminary design line length, $K_{G}$ is Taki number per $\mathrm{km}, S_{G}$ is experimental design guidance covers area per Taki, $M_{S}$ is land occupied compensation criteria. PLACs as in Equation (12).

$$
E_{6}=\sum_{i=1}^{N} c_{t_{i}} M_{i} R_{i}
$$

$c_{t_{i}}$ is land price in energy base, $M_{i}$ is power plant unit capacity footprint, $R_{i}$ is power plants install capacity, $N$ is power plants number.

Our country lack skill human resources especially in adapting UHV development aspects, despite our country is large population country, so there is much point in reducing HRC. HRC include DTHRCs and TLMCHRs as in Equation (13).

$$
E_{7}=S_{w e} n_{0} \overline{c_{f}}+\sum_{i \in I_{N}} n_{i 0} \eta_{i} m_{0} S_{w e} \overline{c_{y i}}
$$

Within $n_{0}$ is the number of staff per produce $1 \mathrm{kwh}, \overline{C_{f}}$ is average wage of power plant worker, $n_{i 0}$ is per staff number engage in coal trans through using vehicle $i, \overline{c_{y i}}$ is staff average wage using vehicle $i$.

TLMCHRs refer to felling trees and line maintenance need human resource cost, as in Equation (14). 


$$
E_{8}=\sum_{i=1}^{n} c_{k} L_{i} \lambda_{k}+n_{w} L_{i} c_{w}
$$

$c_{k}$ represent HRC per length due to fell trees, $\lambda_{k}$ is the ration between need fell trees and total line, $n_{w}$ is the maintenance number per transmission line length, $c_{w}$ is the average wage of run and maintenance staff.

\subsection{Indirect Social Cost Assessment Index System}

According to some international researchers, residents living along the route is impacted by audible noise, no complaint when audible noise less than $52.5 \mathrm{~dB}(\mathrm{~A})$, there is a small amount of complaints when audible noise exist between $52.5 \mathrm{~dB}(\mathrm{~A})$ and $59 \mathrm{~dB}$ (A), there is large number of complaints when audible noise higher than $59 \mathrm{~dB}(\mathrm{~A})$ in [9]. Therefore, transmission line need noise reduction when the transmission line noise higher than 52.5d BA. Related solve method is formulated through calculation and analysis power line audible noise. Audible noise on the transmission line is extensive researched at home and abroad, Ref [10] through the single-phase wire superposition to calculate entire line noise, and calculate it through different formulate is concluded from the analysis that BPA formula Equation (15) could better reflect actual situation.

$$
\mathrm{SLA}= \begin{cases}120 \lg g+26.4 \lg n+55 \lg d-11.4 \lg D-128.4 & n \geq 3 \\ 120 \lg g+55 \lg d-11.4 \lg D-115.4 & n<3\end{cases}
$$

where $g$ is the maximum potential gradient averages, $n$ is the number of bundled conductors, $d$ is split wire diameter, $D$ is distance from observation point to the corona point. In order to reduce transmission lines audible noise, usually by increasing the diameter of the wire split, the number of bundled conductors, the division split conductor spacing and the average height of the wires on the ground, but the increase in tower height costs too much often rarely used. Thereby lower $1 \mathrm{~dB}(\mathrm{~A})$ expenses as in Equation (16) can be obtained.

$$
E_{9}^{\prime}=\min \left\{\sum_{i=1}^{N_{0}} L_{i}\left(\varepsilon_{2}-\varepsilon_{1}\right) n_{1}, \sum_{i=1}^{N_{0}} L_{i} \varepsilon_{1}\left(n_{2}-n_{1}\right), \sum_{i=1}^{N_{0}} L_{i}\left(\varepsilon_{2}-\varepsilon_{1}\right)\left(n_{2}-n_{1}\right)\right\}
$$

$e_{1}, e_{2}, e_{3}$ is increased wire diameter, number and fee split pitch. $\varepsilon_{1}, \varepsilon_{2}$ is cost per length before and after transmission line being transformed, $n_{1}, n_{2}$ is the number of bundled conductors before and after transmission line being transformed. So ANRCs can be got, as in Equation (17).

$$
E_{9}= \begin{cases}(S L A-[52.5]+1) \times E_{9}^{\prime} & \text { SLA }>52.5 \\ 0 & \text { SLA } \leq 52.5\end{cases}
$$

The sustained development of economy, security of energy supply is an important guarantee, if the power supply is interrupted in power grid transmission process will cause users a great loss, Ref [11] from the power system generation and electricity transmission reliability point of view, electricity accident losses is assessed rely on reliable cost. According to power outages and blackouts every time combine with historical data in social loss costs due to power cut in [12], SCLP when power supply interruption 
time is $T_{i}$ can be obtained, as in Equation (18).

$$
E_{10}=\sum_{i=1}^{p_{i j} \times L_{k}^{\prime}} E_{t 0} T_{i} \beta_{i^{\prime}}
$$

where $p_{l j}$ is transmission line trip frequency per $100 \mathrm{~km} / \mathrm{a}, L_{k}^{\prime}$ is hundredth of the transmission line length, $E_{\text {to }}$ is per unit time social loss caused by power outages in historical data, $T_{i}$ is per power outages time, $\beta_{i}^{\prime}$ is similarity between power outages area and historical data collection area.

\section{Case Study}

The $1000 \mathrm{kV}$ UHV transmission project is taken as an example, 7.06 billion electricity can be transported to load centers annually after project has been completed, conductor use, line length is $640 \mathrm{~km}$, from A (energy base) to B line length is $360 \mathrm{~km}$, from B to C (load center) segment line length is $280 \mathrm{~km}$, static investment is 5.7 billion RMB.

\subsection{Social Benefits Assessment}

Suppose that each unit of electricity can create 3.943 RMB social benefits, 7.06 billion energy is transported from energy base to load center, 24,660,580,000 RMB industry benefits can be got; Based on CASS calculate data combine with China's per capita income, can get direct employment benefits about 2.80724 billion RMB, according to China's per capita social value and create social benefits per $1 \mathrm{kwh}$ can get indirect employment benefits about 22.2701 trillion RMB, social benefits is shown in Table 1 .

\subsection{Social Cost Assessment}

It is known that the line loss rate of $1000 \mathrm{kV}$ and $500 \mathrm{kV}$ were $0.277 \%$ and $0.7 \%$, the electric field intensity of transmission lines were $7.171 \mathrm{kV} / \mathrm{m}$ and $1.457 \mathrm{kV} / \mathrm{m}$, the tower height is respectively $25 \mathrm{~m}$ and $14 \mathrm{~m}$ in the residential zone, distance between sub conductors is respectively $400 \mathrm{~mm}$ and $375 \mathrm{~mm}$, transmission corridor distance is respectively $20 \mathrm{~m}$ and $13 \mathrm{~m}$, integrated circuit fault trip rate is respectively $0.15 \mathrm{bout} /(100$ $\mathrm{km} / \mathrm{a})$ and $0.2 \mathrm{bout} /(100 \mathrm{~km} / \mathrm{a})$, coal consumption is need $310 \mathrm{~g}$ per produce $1 \mathrm{kwh}$ energy, $500 \mathrm{kV}$ of $1000 \mathrm{kV}$ is 4.5 times and above in the transmission line transmission capacity aspect, this paper take 4.5 times, according to the American institute for statistics global insight that 100 to 116 people are need per produce $10 \mathrm{kwh}$, this paper take 116. Suppose coal is transported from A to C, road transport line is $40 \mathrm{~km}$, railway transport line is $600 \mathrm{~km}$, and combine with China's actual, $60 \%$ of coal volume is transported by rail transport, $40 \%$ of coal volume is transported by road transport, per fresh water cost is calculated 1.5 RMB/cubic meter. Direct cost can be got when transport same power as shown in Table 2 .

Table 1. Social income (unit: RMB ten thousand).

\begin{tabular}{ccc}
\hline CIBs & DEBs & IEBs \\
\hline $2,466,058$ & 280,724 & 222,701 \\
\hline
\end{tabular}


Table 2. Direct social costs (unit: RMB ten thousand).

\begin{tabular}{ccccccccccc}
\hline \multirow{2}{*}{ DSCs } & \multicolumn{2}{c}{ ENs } & & EC & & & LC & HRC \\
\cline { 2 - 9 } & CETCs & EACs & ETCs & FRCCs & GRCs & TACCs & PLACs & DTHRCs & TLMCHRs \\
\hline Option one & 46,745 & 7817 & 35,791 & 4312 & 78,041 & 4758 & 18,148 & 5505 & 1565 \\
Option two & 48,072 & 8039 & 36,807 & 4435 & 80,597 & 19,726 & 18,662 & 5653 & 4579 \\
Option three & 46,494 & 7759 & 65,463 & 4280 & 78,623 & 4383 & 23,549 & 5443 & 1018 \\
\hline
\end{tabular}

Case two needs noise reduction to avoid being complained because its audible noise over $52.5 \mathrm{~dB}(\mathrm{~A})$, the minimum noise reduction costs is 2.05 million RMB through comparative analysis several options; And suppose power is recovered need 1 hour per power cut, based on historical data and load center actual situation, fuzzy theory is used to assess the similarity between load center and historical blackout area, social power cut loss cost can be got, this paper take similarity is 0.4 . Indirect costs as shown in Table 3.

A conclusion can be got from Table 3, ANRCs can be reduced effectively through option one and three, and SCLP is lower compare option three to one. Therefore, the option three has the lowest ISCs and best indirect social benefits.

\subsection{Figures and Tables}

Social benefits can be obtained through comparative analysis social costs and social income, as shown Table 4.

Huge social benefits can be obtained through option one from Table 4, and about over 461.73 million RMB can be got option one much more compared to option two, 254.85 million RMB can be got option one much more option three, we can conclude that much

\section{Conclusions}

Based on the UHV engineering practice, social costs and social income assessment index system are built, and social benefits assessment model is introduced according to the gap between costs and income, indirect social benefits can be got through comparative analyzing the gap between option one and the other two options. Conclusions can be inferred as follow.

Direct social costs evaluation index system of UHV can be introduced from environmental protection, energy, land and human resources four aspects, indirect social costs evaluation index system of UHV can be introduced from audible noise reduction and social cost of lost power two aspects, social costs assessment model is systematic and comprehensive introduced; social income assessment index system is introduced from production and employment two aspects. Social benefits assessment model can be systematic and comprehensive introduced. Social benefits of UHV can be systematicly and comprehensively assessed through its model from cases operators. 
Table 3. Indirect social costs (unit: RMB ten thousand).

\begin{tabular}{ccc}
\hline ISCs & ANRCs & SCLP \\
\hline Option one & 0 & 17,684 \\
Option two & 205 & 39,774 \\
Option three & 0 & 8839 \\
\hline
\end{tabular}

Table 4. Social benefits (unit: RMB ten thousand).

\begin{tabular}{ccc}
\hline SBs & SC & SE \\
\hline Option one & 220,366 & $3,247,859$ \\
Option two & 266,539 & $3,247,859$ \\
Option three & 248,496 & $3,247,859$ \\
\hline
\end{tabular}

\section{Acknowledgements}

This work is funded by the Natural Science Foundation of China (51207114).

\section{References}

[1] Zhang, N. and Liu, J.K. (2013) The Ultra-High Voltage Grid Risk Analysis and Its Assessment Framework. Power System Protection and Control, 43, 109-114.

[2] Wang, X.H., Zhang, L.Z. and Cheng, S.J. (2014) Economic Analysis of Pumped-Storage Unit in Electricity System with Multi-Type Power Sources. Power System Protection and Control, 42, 8-15.

[3] Mark, M.G. and Bill, R. (2002) Economic Evaluation of Power Quality. IEEE Power Engineering Review, 22, 8-12. http://dx.doi.org/10.1109/MPER.2002.981339

[4] Zhang, Y.J., Huang, H. and Tang, J. (2010) Economy Comparison of Line's Ice Disaster Cycle Based on Non-Sequential Monte Carlo. Power System Protection and Control, 38, 119-123.

[5] Yang, H., Wang, D. and Liu, D.C. (2015) Establishment of UHV AC Transmission Model and Economical Optimization Strategy. Power System Protection and Control, 43, 91-96.

[6] Kang, C.Q., Zhou, T.R., Chen, Q.X. and Ge, Y. (2009) Assessment Model on Low-Carbon Effects of Power Grid and Its Application. Power System Technology, 33, 1-7.

[7] Dong, L.T. (2006) Research on the Mechanism of RPS Executed in China. North China Electric Power University, Biejing, 48-55.

[8] Ding, W. and Hu, Z.G. (2006) The Research on the Economy Comparison of Ultra High Voltage. Power System Technology, 30, 7-13.

[9] Liu, Z.Y. (2013) UHV AC/DC Power Grid. China Power Press, Beijing.

[10] Yu, J.H., Yang, Y., He, J., Yang, G. and Ji, J. (2009) Evaluation of Audible Noise Predicting Formulas for AC UHV Transmission Lines. High Voltage Engineering, 35, 451-456.

[11] Huang, Y.S. and Ye, S. (2002) Benefit Evaluation Based on Interruption Losses of Power Generation and Transmission. IEEE Power Engineering Society Summer Meeting, Seattle, 31 July 2002, 45-52.

[12] Ling, Z.H., Zhou, Y.H., Gu, H.F., Wang, Y.L. and Hu, Z.H. (2009) An Approach to Estimate Power Transmission Interruption Cost Based on Fuzzy Theory. Power System Technology, 33, 71-74. 
Submit or recommend next manuscript to SCIRP and we will provide best service for you:

Accepting pre-submission inquiries through Email, Facebook, LinkedIn, Twitter, etc. A wide selection of journals (inclusive of 9 subjects, more than 200 journals)

Providing 24-hour high-quality service

User-friendly online submission system

Fair and swift peer-review system

Efficient typesetting and proofreading procedure

Display of the result of downloads and visits, as well as the number of cited articles

Maximum dissemination of your research work

Submit your manuscript at: http://papersubmission.scirp.org/

Or contact sgre@scirp.org 